\title{
HTERT/Survivin/CMV Multipeptide Vaccine
}

National Cancer Institute

\section{Source}

National Cancer Institute. hTERT/Survivin/CMV Multipeptide Vaccine. NCI Thesaurus.

Code C102879.

A vaccine containing multiple peptides derived from the human telomerase reverse transcriptase (hTERT), survivin and cytomegalovirus (CMV), with potential

immunostimulating and antineoplastic activities. Upon administration,

hTERT/survivin/CMV multipeptide vaccine may elicit a cytotoxic T cell (CTL) response against tumor cells espressing hTERT, survivin and CMV. hTERT, the catalytic subunit of telomerase, and the inhibitor of apoptosis (IAP) family member survivin, both often upregulated in tumor cells, play key roles in tumor cell growth and survival. Further, CMV expression is correlated with certain types of cancer. 